\title{
Relação entre disponibilidade hídrica e produtividade do eucalipto em diferentes idades, em Guanhães, Minas Gerais
}

\author{
Maria J. H. de Souza ${ }^{1}$, Aristides Ribeiro ${ }^{2}$, Hélio G. Leite ${ }^{3}$, Fernando P. Leite ${ }^{4} \&$ Rosandro B. Minuzzi $^{5}$
}

\section{RESUMO}

Para realização deste trabalho, estudou-se a produtividade de povoamentos de eucalipto e a disponibilidade hídrica do solo na região de Guanhães, Minas Gerais. Para tal, avaliaram-se as precipitações ocorridas nas estações chuvosas (PEC), os componentes do balanço hídrico, os índices anuais de aridez (la), hídrico (Ih) e de umidade (Im) do solo e o incremento periódico mensal (IPM), médio anual, durante o período de 1985 a 1998. A produtividade de madeira foi influenciada pela PEC, em que os menores valores de IPM foram observados nos anos precedidos de estação chuvosa seca ou muito seca, e os maiores nos anos precedidos de estação chuvosa, classificada como chuvosa ou muito chuvosa. Para os períodos de aumento e de diminuição na PEC verificou-se correlação com o IPM, obtendo-se um $\mathrm{R}^{2}$ acima de 0,80 . Para o aumento e redução de $100 \mathrm{~mm}$, na PEC o IPM aumentou 0,51 $\mathrm{m}^{3} \mathrm{ha}^{-1} \mathrm{mês}^{-1}$, e reduziu $0,80 \mathrm{~m}^{3}$ ha $^{-1}$ mês $\mathrm{s}^{-1}$, respectivamente. Salvo algumas exceções, valores superiores de IPM foram constatados nos anos posteriores aos anos com Im e Ih mais elevados e nos anos precedidos por Im negativo, constatou-se redução no IPM, o qual, no entanto, foi superior para a faixa etária de 3 a 5 que para a de 5 a 7 anos e o índice de local médio foi de 28,90.

Palavras-chave: produtividade florestal, balanço hídrico seqüencial, estação chuvosa, índices de umidade do solo, taxa de crescimento

\section{Relationship between water availability and eucalyptus productivity at different ages in Guanhães region, Minas Gerais state}

\begin{abstract}
A study concerning the productivity of eucalyptus and the soil water availability was carried out in Guanhães region, Minas Gerais State, Brazil. Evaluations were accomplished for precipitation events occurring over the rainy seasons (PEC), water balance components, annual indices for aridity (la), hydric (Ih) and moisture (Im), as well as the monthly periodic increment (IPM), annual average, over the period from 1985 to 1998. The wood productivity was affected by PEC, and the lowest IPM values were observed in the years preceded by either dry rainy season or very dry rainy season, whereas the highest IPM values were observed in those years preceded by rainy season classified as rainy or very rainy one. For periods with increased or decreased PEC, a correlation of this variable with IPM was verified, and a $R^{2}$ value above 0.80 was obtained. For an increase and reduction of $100 \mathrm{~mm}$ in PEC, the IPM showed an increase of $0.51 \mathrm{~m}^{3} \mathrm{ha}^{-1} \mathrm{month}^{-1}$ and a reduction of $0.80 \mathrm{~m}^{3} \mathrm{ha}^{-1}$ month $^{-1}$, respectively. With some exceptions, higher IPM values were observed in the years subsequent to the years with higher Im and $\mathrm{lh}$; and in those years preceded by a negative $\mathrm{Im}$, a reduction was verified in IPM. The IPM was higher for the age range from 3 to 5 than for that from 5 to 7 years, whereas the value for the average local index was 28.90 .
\end{abstract}

Key words: forest productivity, sequential water balance, rainy season, moisture indexes, eucalyptus growth rate

1 Departamento de Agronomia, UFVJM, CEP 39100-000, Diamantina, MG. Fone: (38) 3532 1200, (38) 3531 0243. E-mail: mariahatem@yahoo.com.br, mjhatem@ufv.br 2 Departamento de Engenharia Agrícola, UFV, CEP 36571-000, Viçosa, MG. Fones: (31) 3899 1906, (31) 3899 2729. E-mail: ribeiro@ufv.br

${ }^{3}$ Departamento de Engenharia Florestal, UFV, CEP 36571-000, Viçosa, MG. Fone: (31) 3899 1203. E-mail: hgleite@ufv.br

${ }^{4}$ Pesquisador, Empresa Celulose Nipo-Brasileira S.A. - CENIBRA. Fone: (31) 3829 5017. E-mail: fernando.leite@cenibra.com.br

${ }^{5}$ Doutorando do Departamento de Engenharia Agrícola, UFV, Viçosa, MG. Fone: (31) 3899 1900. E-mail: megadetheoro@bol.com.br 


\section{INTRODUÇÃO}

O meio ambiente influencia o crescimento, a estrutura e a reprodução dos vegetais em razão da maior ou menor disponibilidade de calor, luz, água, elementos e compostos. Tendo em vista a complexidade de suas inter-relações, é comum se estudar separadamente os efeitos dos fatores ambientais no desenvolvimento dos vegetais (Billings, 1952).

A influência climática no crescimento das árvores tem sido estudada por vários autores (Woollons et al., 1997; Bergh et al., 1998; Wensel \& Turnblom, 1998 e Yet, 1997, apud Yet et al., 2000; Soares, 1999; Maestri, 2003). Os principais elementos climáticos que afetam o crescimento das árvores são: a irradiância solar, a temperatura e a disponibilidade hídrica. A radiação solar é a principal fonte de energia para o processo fotossintético (O’brien, 1995); a temperatura influencia vários processos fisiológicos, como a fotossíntese, a respiração, a transpiração e a divisão celular; e a água é fundamental em todos os processos fisiológicos e bioquímicos (Campos, 1970; Pereira, et al., 2002): portanto, o desenvolvimento dos plantios florestais apresenta forte dependência das disponibilidades hídricas e energéticas do meio ambiente.

A relação entre a disponibilidade hídrica e a produtividade florestal, ocorre devido aos efeitos diretos e indiretos da deficiência de água no crescimento das árvores; dentre esses efeitos, destacam-se: diminuição da taxa fotossintética por aumento da resistência estomática (Vose \& Swank, 1994); diminuição do aporte nutricional das árvores, via fluxo de massa e difusão; diminuição da velocidade de mineralização da matéria orgânica e, em grau mais elevado, o próprio colapso funcional, a nível citoplasmático e tissular, em virtude da deficiência hídrica (Sands \& Mulligan, 1990).

Maestri (2003) estudando a influência das variáveis ambientais no incremento corrente anual em altura dominante de povoamentos de Eucalyptus grandis, concluiu que as variáveis mais significativas foram a precipitação pluviométrica, a evapotranspiração potencial, a temperatura máxima e a temperatura mínima. Stape (2002) concluiu que o aporte hídrico foi o principal elemento controlador da produtividade do eucalipto (clone de Eucalyptus grandis x Eucalyptus uroplhylla) e do uso de recursos naturais, assim como em períodos de déficit hídrico, a produção de madeira é significativamente afetada.

A disponibilidade hídrica do solo é influenciada pelas condições térmicas e pela distribuição espaço-temporal das precipitações, influenciando os processos de evapotranspiração e absorção dos nutrientes e, conseqüentemente, a produtividade das plantas. Souza et al. (2006) verificaram que embora haja um ganho em produtividade de eucalipto, na bacia do Rio Doce, em anos com maiores totais de chuva, as perdas em anos secos é um pouco maior.

O balanço hídrico pode ser entendido como a contabilização dos ganhos e perdas de água, em determinado volume de solo. Os ganhos são constituídos, basicamente, pela precipitação pluvial, enquanto as perdas ocorrem por evapotranspiração, percolação profunda e escoamentos superficial e subsuperficial de saída. O volume de solo é definido pela profundidade efetiva do sistema radicular, em que se observa a absorção de água pelas raízes.
Como subprodutos do balanço hídrico, tem-se os índices de umidade. Thornthwaite (1948) citado por Sellers (1965), definiu o índice de umidade (Im) como sendo a razão entre a diferença anual entre o suprimento excedente de água (EXC) e 60\% da deficiência hídrica anual (DEF) e a necessidade hídrica, que ocorre em uma superfície vegetada sem limitação de água (ETP), ou seja, Im = (EXC 0,6 DEF) / ETP. Thornthwaite \& Mather (1962) citado por Sellers (1965), omitiram o fator 0,6, sendo o Im calculado como a diferença entre o índice hídrico (EXC/ETP) e o índice de aridez (DEF/ETP).

Os índices de umidade, aridez e hídrico, servem de base para a classificação climática de Thornthwaite (Pereira et al., 2002), ou seja, com Im acima de 100; o clima pode ser classificado como superúmido, acima de 20 e abaixo de 100 como úmido, entre 0 e 20 como subúmido, entre -20 e 0 como subúmido seco, entre -40 e -20 como semi-árido e abaixo de -40 como árido. Entre outras aplicações, estes índices são utilizados, também, em zoneamentos agroclimatológicos (Teixeira \& Azevedo, 1994) e como indicadores do nível de água no solo.

Com base no exposto objetivou-se, com o presente trabalho, fazer uma análise comparativa da produtividade vegetal e disponibilidade hídrica, em região de altitude elevada da Bacia do Rio Doce, Minas Gerais, para plantios de eucalipto com diferentes idades; procurou-se então, explicar a variação do incremento periódico mensal, médio anual, tomando-se como modelo as precipitações ocorridas na estação chuvosa e os componentes do balanço hídrico.

\section{MATERIAL E MÉTODOS}

O estudo foi realizado na região de Guanhães, Minas Gerais, cuja área pertencente à bacia do Rio Doce. Esta região engloba várias cidades - como Sabinópolis, Virginópolis, Correntinho, Penhora - inclusive a cidade de Guanhães, como pode ser visualizado na Figura 1.

Os dados de temperatura média e precipitação foram fornecidos pela Empresa Florestal Celulose Nipo-Brasileira CENIBRA, e obtidos em uma estação meteorológica convencional, localizada a $18^{\circ} 48^{\prime} \mathrm{S}, 42^{\circ} 58^{\prime} \mathrm{W}$ e $802 \mathrm{~m}$ de altitude.

O clima de Guanhães, segundo a classificação climática de Köppen, é Aw, Tropical chuvoso de savana, ou seja, inverno seco e chuvas máximas no verão. Conforme a classificação climática de Thornthwaite, o clima de Guanhães é $\mathrm{C}_{2} \mathrm{r} \mathrm{B}_{4}{ }_{4} \mathrm{a}$, isto é, clima subúmido, com deficiência de água pequena ou nula, mesotérmico (Souza et al., 2003). A precipitação anual é de $1212 \mathrm{~mm}$ e a temperatura média de $22,2^{\circ} \mathrm{C}$ (Souza et al., 2003). O relevo é suave a forte ondulado, com solos profundos, argilosos e pouco férteis.

O balanço hídrico foi calculado para o período de janeiro de 1985 a dezembro de 1998, com base nos dados mensais de temperatura média e precipitação (Figura 2), de acordo com metodologia proposta por Thornthwaite \& Mather (1955). Para valores mensais, esta metodologia foi detalhada por Pereira et al. (2002). Considerou-se, para tal, 


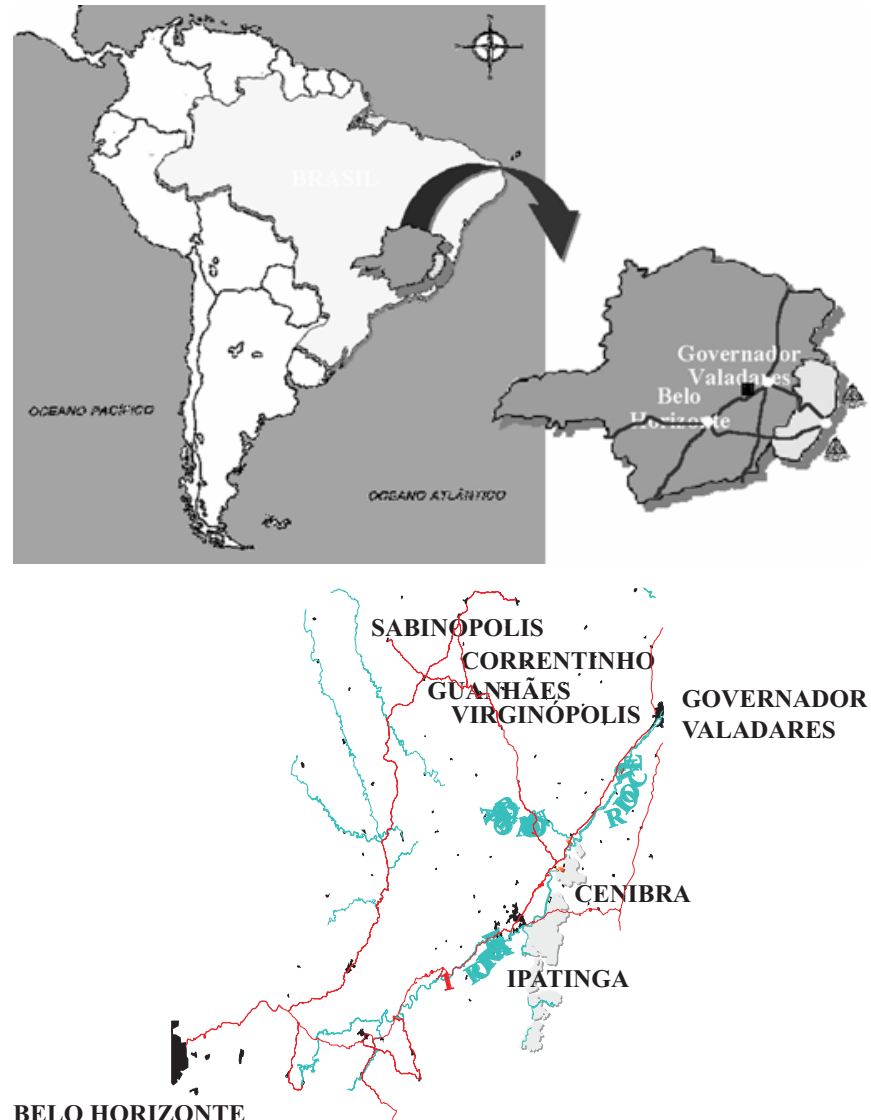

BELO HORIZONTE

Figura 1. Localização da região de Guanhães no Estado de Minas Gerais

uma capacidade de armazenamento de água no solo (CAD) de $200 \mathrm{~mm}$. Utilizou-se este valor por se encontrar na faixa encontrada na literatura. Segundo Pereira et al. (2002) para espécies florestais a CAD varia de 150 a $300 \mathrm{~mm}$. Stape \& Gomes (1996) utilizaram uma CAD de $200 \mathrm{~mm}$ para contabilização do balanço hídrico de Thornthwaite \& Mather (1955) em plantios de eucalipto (E. grandis x urophylla) com idade variando de 3 a 8 anos. Neves (2000) determinou que a CAD para plantios de eucalipto, no litoral do Espírito Santo, para árvores com nove anos, foi de $168 \mathrm{~mm}$, enquanto Sacramento Neto (2001) trabalhando com plantios jovens de eucalipto (1 e 2 anos), na região de Belo Oriente na bacia do Rio Doce, determinou que em solos de baixada a CAD variou de 137 a $171 \mathrm{~mm}$ e em solos de encosta esta variação foi de 70 a $110 \mathrm{~mm}$.
Calcularam-se os componentes do balanço hídrico, ou seja, a evapotranspiração potencial, o armazenamento de água no solo, a evapotranspiração real, a alteração do armazenamento de água no solo, a deficiência hídrica e o excedente hídrico e, também, a evapotranspiração relativa, sendo esta a razão entre a evapotranspiração potencial e a evapotranspiração real (Doorenbos \& Kassam, 1979). A partir dos valores mensais, calcularam-se os anuais.

De posse dos valores anuais, relativos ao período de 1985 a 1998, de evapotranspiração potencial, deficiência hídrica e excedente hídrico, determinaram-se os índices de aridez, hídrico e de umidade, desenvolvidos por Thornthwaite (1948) citado por Sellers (1965). Vianello \& Alves (1991) apresentam as equações para determinação desses índices, com base no balanço hídrico proposto por Thornthwaite \& Mather, em 1955, como:

$$
\begin{gathered}
\text { Ih }=100 \times \text { EXC/ETP } \\
\text { Ia }=100 \times \text { DEF/ETP } \\
\text { Im }=\text { Ih }- \text { Ia }
\end{gathered}
$$

em que Ih é o índice hídrico; Ia é o índice de aridez; Im é o índice de umidade; EXC é o excedente hídrico anual; DEF é a deficiência hídrica anual e ETP é a evapotranspiração potencial anual.

Os períodos chuvosos foram avaliados empregando-se a técnica dos quantis, metodologia esta desenvolvida por Pinkayan (1966); para tal, foram utilizados os dados de precipitação referentes ao semestre mais chuvoso, denominado 'estação chuvosa'. Classificaram-se, segundo Xavier (2001), as estações chuvosas como: muito seca (MS), seca (S), normal $(\mathrm{N})$, chuvosa (C) e muito chuvosa (MC) para o que se utilizaram os quantis $\mathrm{Q}(0,15), \mathrm{Q}(0,35), \mathrm{Q}(0,65), \mathrm{Q}(0,85)$, respectivamente, como limites para essas classificações.

Em geral, a metodologia dos quantis para estudos de precipitação agrupa os períodos de maior ou menor ocorrência de precipitação com duração de quatro meses, denominados quadra chuvosa. Devido às características do local de estudo e, também, para a aplicabilidade em estudos florestais, fez-se opção por trabalhar com períodos de seis meses, aqui denominados estação chuvosa.

Quantificou-se o ganho de volume médio anual de madeira $\left(\mathrm{m}^{3} \mathrm{ha}^{-1}\right)$, utilizando-se dados do inventário florestal contínuo, realizado entre 1986 e 1998. Trabalhou-se com 88

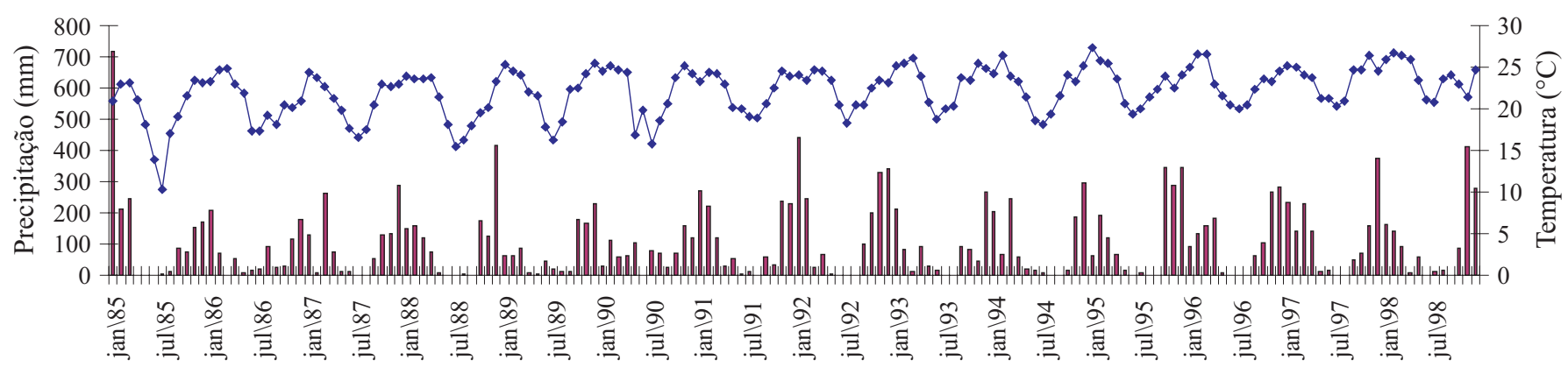

Figura 2. Precipitação e temperatura média do ar em Guanhães, Minas Gerais, média mensal para o período de 1985 a 1998 
talhões. A idade das árvores envolvidas neste estudo, variou de 3 a 7 anos. Como estratégia de estudo, as análises dos ganhos de volume foram agrupadas para as faixas etárias de 3 a 5 e de 5 a 7 anos, o que pode ser justificado pelo fato do eucalipto, apresentar na fase inicial ( 0 a 5 anos) uma taxa de crescimento elevada, enquanto em idade mais adulta esta taxa tende a ser menor.

Calculou-se o incremento periódico anual (IPA) com base no intervalo entre duas medições do inventário, conforme metodologia apresentada por Campos \& Leite (2002). O incremento periódico mensal (IPM) foi obtido dividindo-se o IPA pelo número de meses entre as duas mensurações florestais consecutivas, sendo este IPM contabilizado no ano da última medição.

Os índices de local foram obtidos, para cada talhão, empregando-se o método da curva-guia e o modelo de Schumacher, conforme Campos \& Leite (2002), com base na idade índice de 72 meses.

\section{RESULTADOS E DISCUSSÃO}

A precipitação total anual média e a temperatura média mensal em Guanhães, MG, para o período estudado, podem ser visualizadas na Figura 3. Observa-se que existe uma estação seca bem definida, sendo o trimestre de junho a agosto o menos chuvoso. A precipitação ocorrida nesse trimestre corresponde a 2,8\% do total anual precipitado e o trimestre menos chuvoso coincide com os meses de inverno, ou seja, época em que são observadas as menores temperaturas.

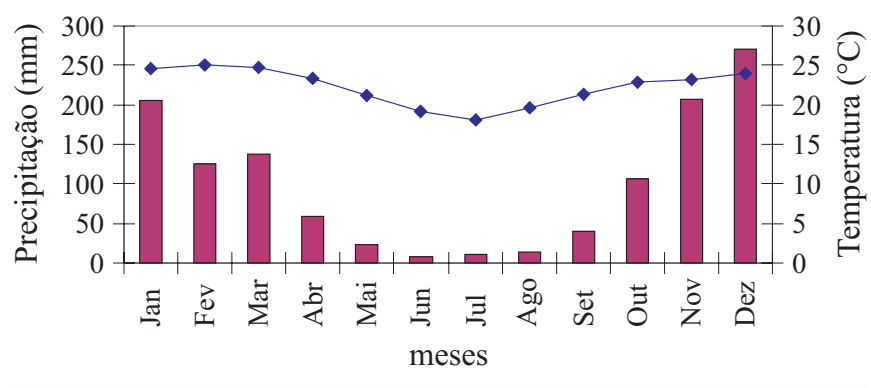

Figura 3. Precipitação total e temperatura média mensal em Guanhães, Minas Gerais, média para o período de 1985 a 1998
Verifica-se que os meses com maior ocorrência de chuvas correspondem àqueles de outubro a março (Figura 3), sendo este período denominado 'estação chuvosa'; para o trimestre de outubro a dezembro, a precipitação acumulada representa $48 \%$ da precipitação total e no trimestre de janeiro a março o total precipitado corresponde a 39\% do total anual; desta forma, o total precipitado na estação chuvosa se refere a $87 \%$ do total anual.

A Figura 4 apresenta o total precipitado em cada estação chuvosa (outubro a março), referente ao período de 1985 a 1998 e sua classificação, obtida por meio da técnica dos quantis, isto é, muito seca (MS), seca (S), normal (N) chuvosa (C) e muito chuvosa (MC).

A Figura 4 mostra que as estações chuvosas classificadas como MC ocorreram durante os anos de 1991/1992, de 1995/ 1996 e de 1996/1997. Aquelas classificadas como MS ocorreram durante os anos de 1985/1986, de 1986/1987 e de 1989/1990. As estações chuvosas nos anos de 1993/1994 e de 1994/1995 foram classificadas como S, enquanto nos anos de 1992/1993 foram classificadas como C. Durante quatro estações chuvosas, dentre as treze estudadas, o comportamento foi normal, e estas classificadas como $\mathrm{N}$.

A Figura 5 apresenta os resultados do balanço hídrico seqüencial, para o período, e a variação da deficiência hídrica do excedente hídrico e do armazenamento de água no solo, em Guanhães, MG.

O efeito do total precipitado nas estações chuvosas (Figura 4) é observado não apenas nas deficiências hídricas mas, também, nos excedentes hídricos e no armazenamento de água no solo, durante o período estudado; por um lado, nas estações chuvosas caracterizadas como MS e S, observamse valores menores de excedentes hídricos e níveis mais baixos de armazenamento de água no solo, porém nos anos MC e C, os excedentes hídricos e o armazenamento de água no solo apresentam valores mais elevados.

A deficiência hídrica, média para o período estudado, foi de $194 \mathrm{~mm}$ anuais, enquanto o excedente hídrico, médio para o período, foi de $316 \mathrm{~mm}$. Com relação ao armazenamento de água no solo (ARM), o valor médio mensal do período foi de 119 mm. Em 76\% dos meses estudados (118 meses dos 156 meses totais), os valores de ARM no solo foram inferiores a $200 \mathrm{~mm}$.

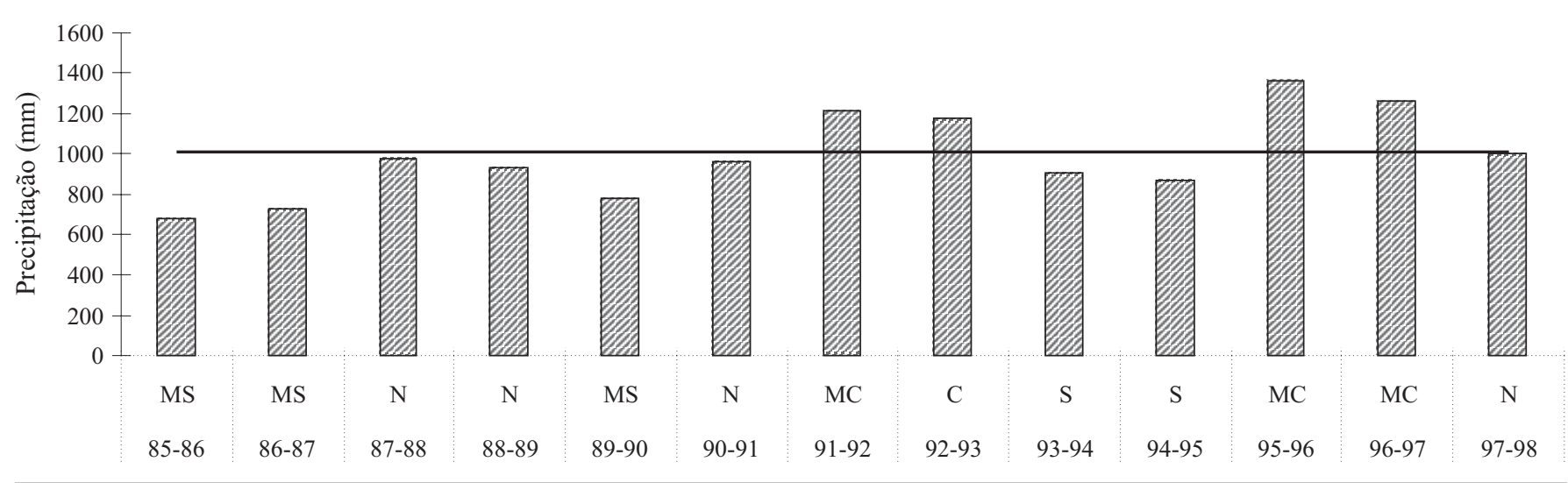

Figura 4. Precipitação total em cada estação chuvosa, outubro a março, no período de 1985 a 1998, e sua classificação, segundo a técnica dos quantis, para Guanhães. A linha cheia representa a média, MS é muito seca, S é seca, N é normal, C é chuvosa e MC é muito chuvosa 

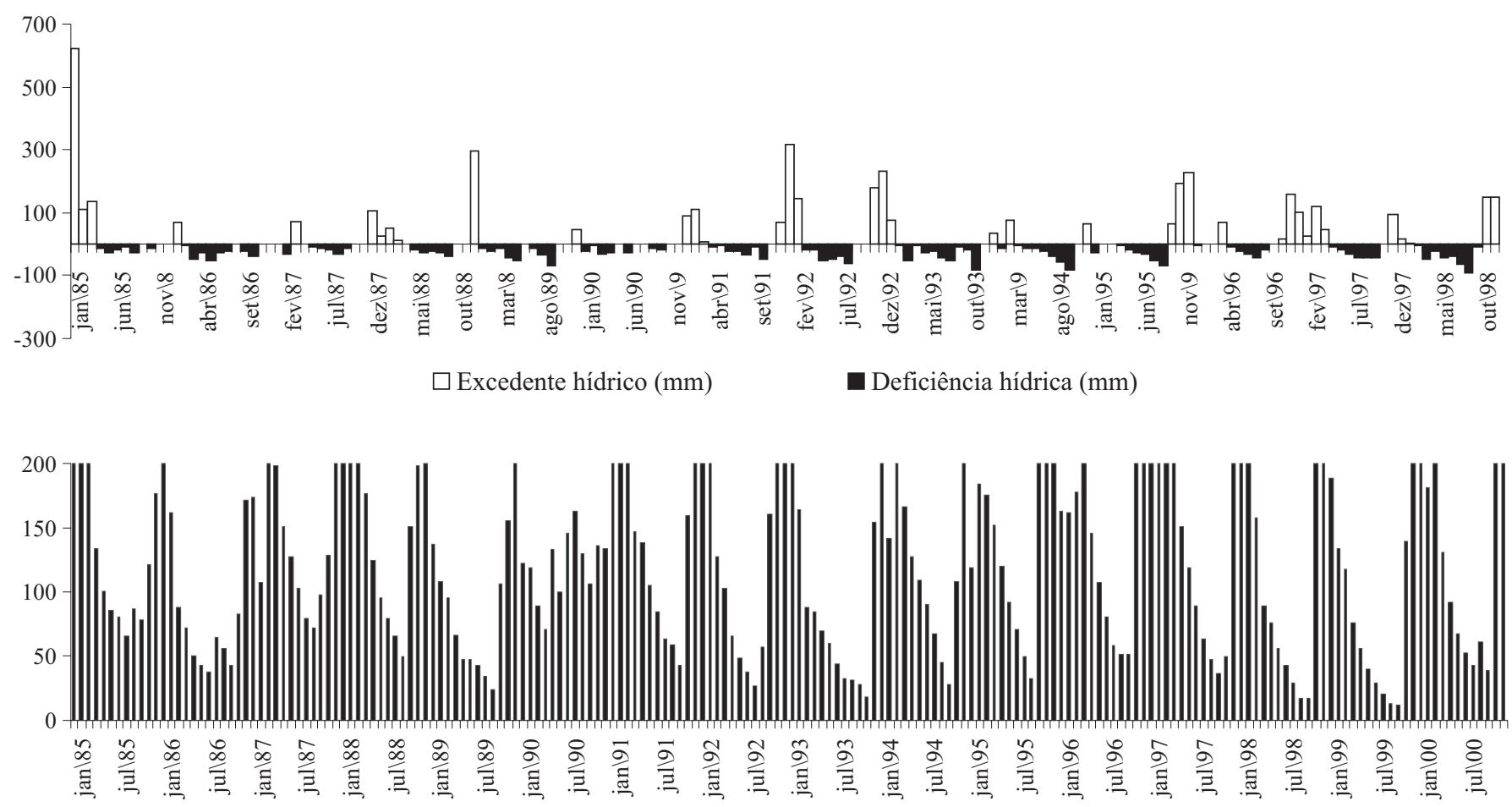

Armazenamento (mm)

Figura 5. Variação mensal do excedente hídrico, da deficiência hídrica e do armazenamento de água no solo (mm) no período de 1985 a 1998 , para Guanhães, Minas Gerais

No período de 1985 a 1998, o armazenamento de água no solo atingiu níveis mais baixos nos meses de março a outubro de 1986, sendo o ARM médio de 56 mm a a estação chuvosa precedente classificada como muito seca MS. Nos meses de março a novembro de 1993 o ARM médio foi de $50 \mathrm{~mm}$, embora a estação chuvosa de 1992/1993 tenha sido classificada como C, aquela do período de 1993/1994 o foi classificada como S, influenciando, portanto, para que o ARM do período de março a novembro de 1993 fosse baixo. Nos meses de abril a outubro de 1998 o ARM médio foi de 46 mm e a estação chuvosa de 1997/1998, classificada como N.

O armazenamento de água no solo é influenciado por vários fatores climáticos, e também pelas características físicas do solo, que não foram consideradas neste estudo. O armazenamento de água no solo é afetado, sobretudo, pela precipitação e pela demanda evaporativa do local, sendo esta, por sua vez, afetada pela disponibilidade energética, ou seja, radiação solar e temperatura. Períodos de alta disponibilidade energética apresentam valores maiores de temperatura e, conseqüentemente, demanda evaporativa maior, o que explica a razão pela qual em alguns períodos descritos acima, o ARM médio tenha sido baixo, mesmo após o período ter sido precedido por uma estação chuvosa $\mathrm{N}, \mathrm{C}$ ou até mesmo MC.

Tem-se, na Figura 6, a evapotranspiração potencial (ETP) e a evapotranspiração real (ETR), em mm, e a evapotranspiração relativa (ETP/ETR), para o período estudado. A ETP anual de Guanhães foi 1103 mm, e a ETR anual foi 909 mm, enquanto a evapotranspiração relativa (ETR/ ETP) média foi 0,82 .
A Figura 7 apresenta os índices de aridez (Ia), hídrico (Ih) e de umidade (Im); nela, observa-se influência do total precipitado na estação chuvosa (Figura 4), antecedente e/ou a que se iniciava no ano, sobre os valores de índice hídrico. Os maiores valores de Ih ocorreram nos anos de 1985, 1992, 1995 e 1988, sendo superiores a 20, significando que esses anos podem ser classificados como úmidos, de acordo com a metodologia proposta por Thornthwaite, para classificação climática (Pereira et al., 2002). Em 1992, a estação chuvosa antecedente (1991/1992) foi classificada como MC e a que se iniciou naquele ano (1992/ 1993) foi classificada como C; em 1995, a estação chuvosa iniciada no ano foi MC, enquanto em 1988 a antecedente e a seguinte foram classificadas como $\mathrm{N}$.

Nos anos em que a estação chuvosa (EC) antecedente e/ ou a iniciada no ano foram MS ou S observa-se, na maioria dos anos, que os valores de índice de aridez (Ia) são superiores a 20. Conseqüentemente, índices de umidade (Im) negativos foram observados nos anos de 1986 (EC 1986/1887 MS), 1989 e 1990 (EC 1989/1990 MS e 1990/1991 N) sendo esses anos classificados como subúmidos secos - bem como em 1993 (EC 1993/1994 S) - ano classificado como semi-árido. Ressalta-se que, além da influência do total precipitado, esses índices também dependem da temperatura que afeta a necessidade hídrica potencial (ETP) necessária à quantificação do EXC e da DEF, os quais afetam os índices hídricos e de aridez e, também, o índice de umidade final.

Na Tabela 1 são apresentados o número de lotes, o IPM médio, a idade média em anos, o índice de local médio e o coeficiente de variação do IPM, para os anos contemplados 

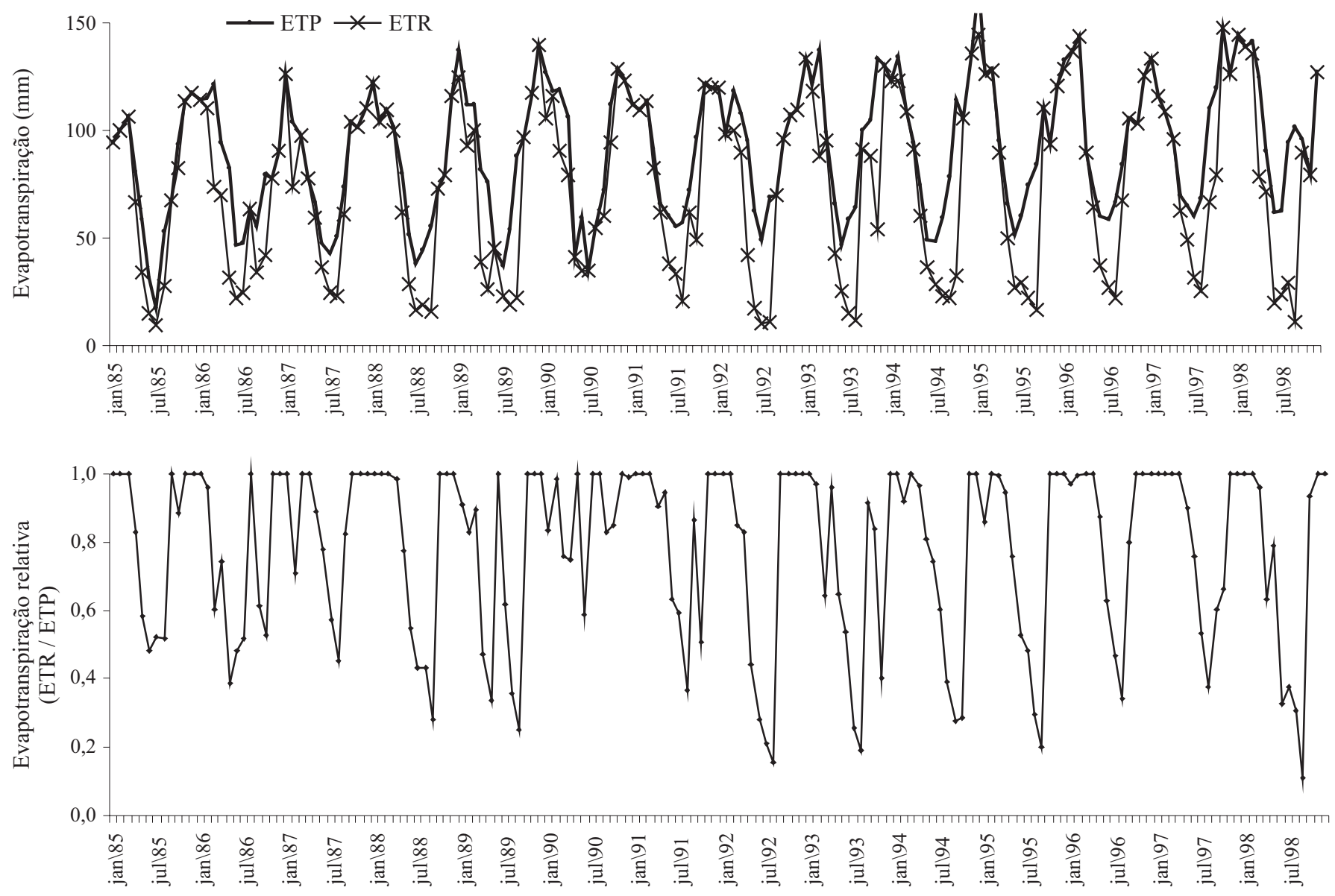

Figura 6. Evapotranspiração potencial (ETP) e evapotranspiração real (ETR), e evapotranspiração relativa (ETR/ETP), em mm, durante o período de 1985 a 1998 em Guanhães, MG

no presente estudo, nas duas faixas etárias das árvores. Verifica-se, nesta tabela que, em média, o coeficiente de variação foi inferior a $20 \%$ para ambas as faixas etárias.

Na Figura 8 são apresentados a variação do incremento periódico mensal e o desvio padrão, para as faixas etárias das árvores de 3 a 5 anos, 5 a 7 anos e de 3 a 7 anos, em
Guanhães. Nota-se que o incremento periódico mensal (IPM) foi maior para a faixa etária de 3 a 5 anos que para a de 5 a 7 anos. O valor médio para a idade de 3 a 5 anos foi de $4,46 \mathrm{~m}^{3} \mathrm{ha}^{-1} \mathrm{mês}^{-1}$, enquanto para a faixa etária de 5 a 7 anos foi de $3,67 \mathrm{~m}^{3}$ ha $^{-1}$ mês $^{-1}$ (Tabela 1). Verifica-se que, ao longo do período estudado, o comportamento é o

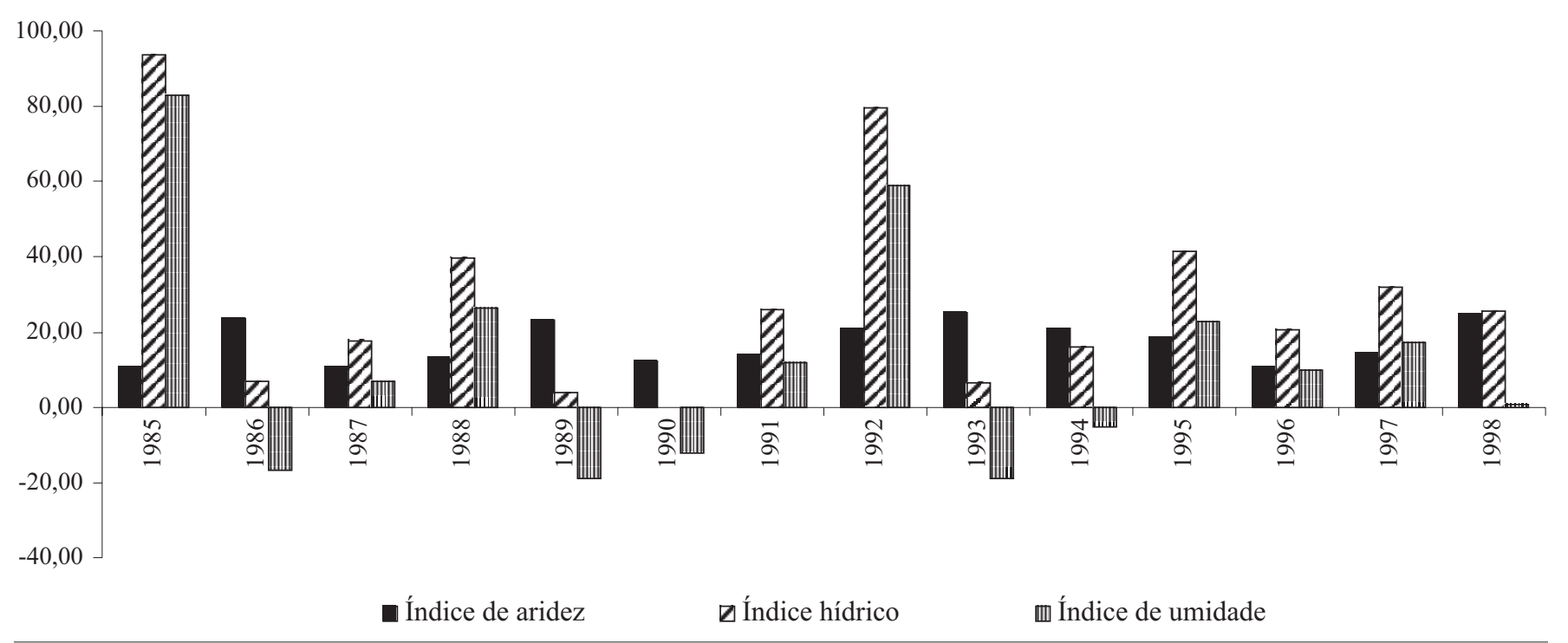

Figura 7. Índices de aridez, hídrico e de umidade 
Tabela 1. Número de lotes, IPM médio, idade média em anos, índice de local médio, número de fustes por hectare e coeficiente de variação do IPM, para os anos envolvidos neste estudo, nas duas faixas etárias

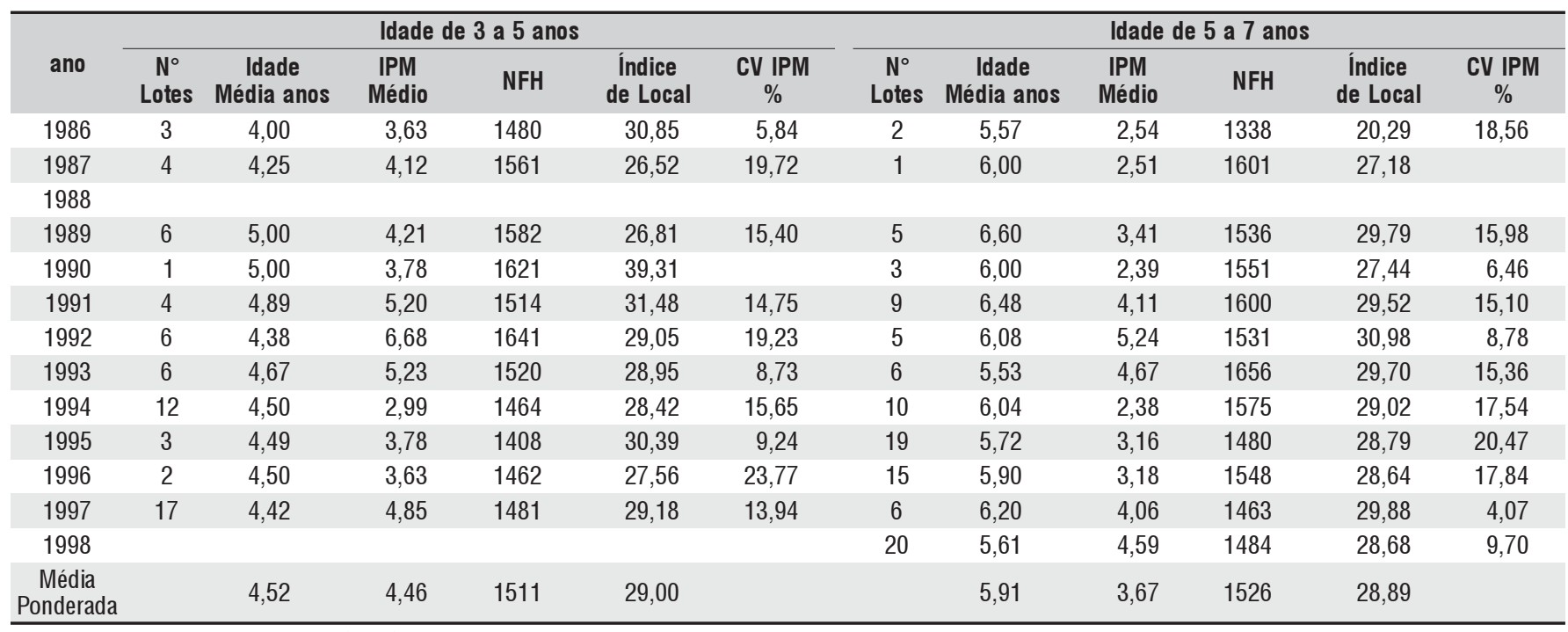

IPM - incremento periódico mensal, em $\mathrm{m}^{3}$ ha $^{-1}$ mês $^{-1}$; NFH - número de fustes por hectare médio e $0 \mathrm{CV}$ - coeficiente de variação
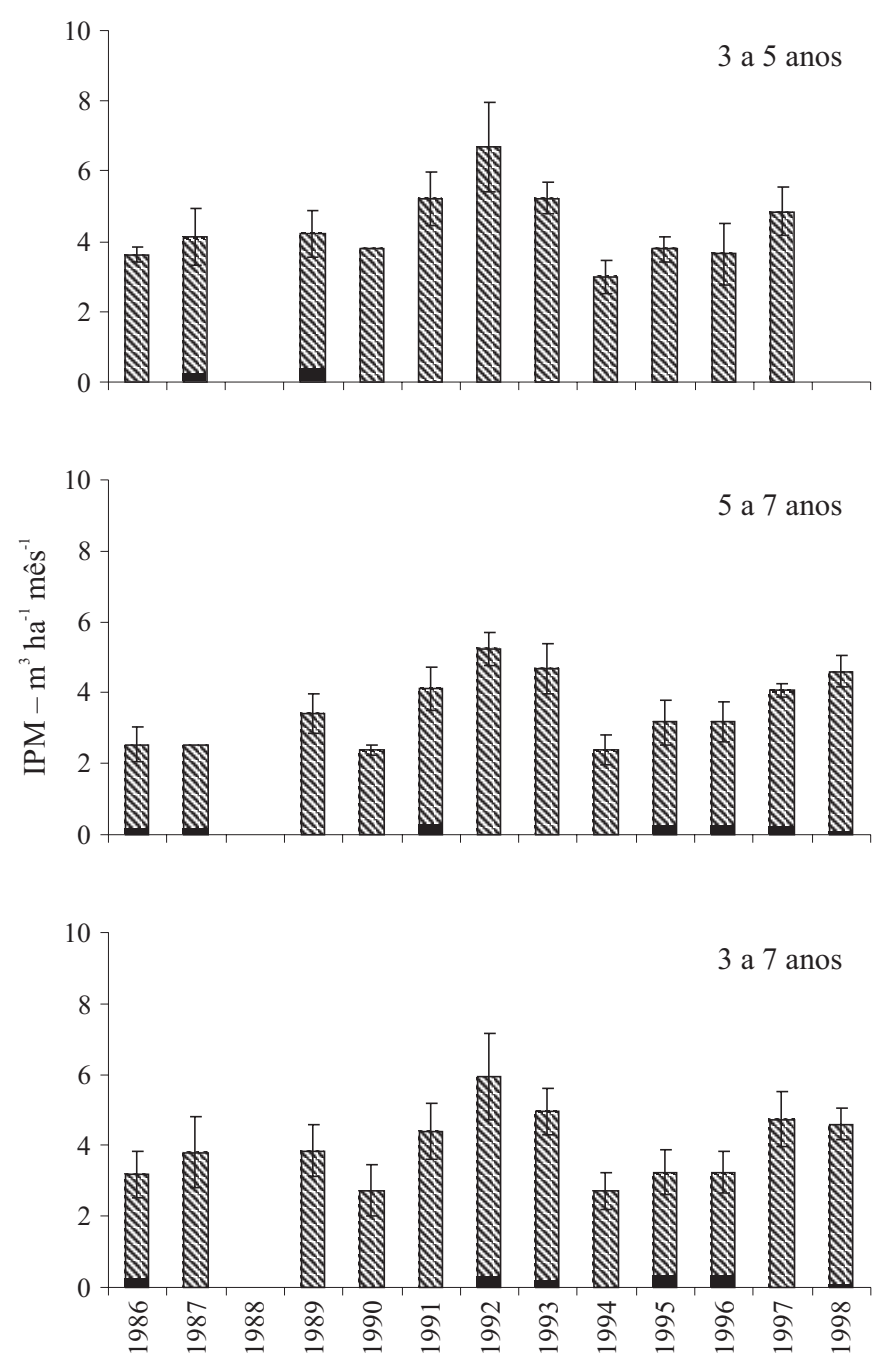

Figura 8. Incremento periódico médio mensal e desvio padrão, em $\mathrm{m}^{3}$ ha $^{-1}$ mês $^{-1}$, para as faixas etárias das árvores de 3 a 5, de 5 a 7 e de 3 a 7 anos em Guanhães, Minas Gerais mesmo para as duas faixas etárias, com aumento no IPM, ao longo dos anos de 1986 a 1992, e redução do IPM de 1992 a 1996.

Comparando-se o IPM obtido nos diferentes anos contemplados neste estudo (Figura 7), com o total precipitado em cada estação chuvosa (Figura 3), conclui-se que o IPM foi menor nos anos precedidos de estação chuvosa classificada como seca (S) ou muito seca (MS), para ambas as faixas etárias estudadas, exceto para o ano de 1996, que apresentou um dos mais baixos IPM (3,24 m ha-1 mês $\left.{ }^{-1}\right)$ e a estação chuvosa precedente foi classificada como muito chuvosa, MC, sendo esta a de maior precipitação acumulada (1366 mm); isto ocorreu, provavelmente, porque as árvores não se haviam recuperado do período seco durante as duas estações chuvosas anteriores (classificadas como secas) comprometendo, deste modo, o aparato fotossintético e/ou o alto excedente hídrico pode ter influenciado negativamente (Figura 5).

A produtividade foi superior nos anos precedidos de estações chuvosas, classificadas como chuvosas (C) ou muito chuvosa (MC), ou seja, os valores IPM foram maiores (Figuras 4 e 8). Os maiores valores de IPM foram obtidos nos

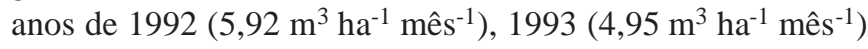
e $1997\left(4,73 \mathrm{~m}^{3} \mathrm{ha}^{-1}\right.$ mês $\left.^{-1}\right)$, os quais foram precedidos de estações chuvosas classificadas como MC (1991/1992), C (1992/1993) e MC (1996/1997).

Comparamdo-se os incrementos periódicos mensais (IPM) com os índices hídricos (Ih), de aridez (Ia) e de umidade (Im), não se verifica comportamento semelhante entre os índices calculados e os valores de IPM, salvo algumas exceções. Para todas as faixas etárias nota-se que no ano de 1992, seguido de 1993, os IPM foram os maiores no período estudado (Figura 8), ressaltando que em 1992, o Ih e o Im foram um dos maiores no período, ou seja, 79,8 e 58,8 (clima úmido), respectivamente (Figura 6). Percebe-se que em 1990 e 1994, ocorreu redução no IPM para as duas faixas etárias, 
sendo que, em 1989, 1990 e em 1993, os índices de umidade foram negativos (em 1989 e 1990 clima subúmido seco e em 1993 clima semi-árido, segundo a metodologia de Thornthwaite). Observa-se também, entre os anos de 1995 a 1998, tendência positiva no incremento do IPM, visto que, nesses anos, o Im foi positivo e o Ih foi superior a 20.

Ao relacionar o total precipitado na estação chuvosa finalizada em cada ano com o incremento periódico mensal (IPM) nas três faixas etárias, verifica-se aumento na precipitação na estação chuvosa (PEC) e nos IPM entre 1986 a 1992. No período de 1992 a 1995, observa-se decréscimo nas
PEC e IPM. Correlacionando os IPM e as PEC relativos aos dois períodos, obteve-se uma relação linear. Esta correlação e os coeficientes de determinação $\left(\mathrm{R}^{2}\right)$, são apresentados na Figura 9.

Quanto ao período de 1986 a 1992, o IPM respondeu positivamente à maior disponibilidade de água no solo, conforme as equações obtidas (Figura 9). Neste período, o ganho de volume médio foi de 0,55 e $0,56 \mathrm{~m}^{3} \mathrm{ha}^{-1} \mathrm{mês}^{-1}$, para as faixas etárias de 3 a 5 e de 5 a 7 anos, respectivamente tendo, para a faixas etárias de 3 a 7 anos, um ganho de volume de $0,51 \mathrm{~m}^{3} \mathrm{ha}^{-1}$ mês $^{-1}$ para um aumento correspondente
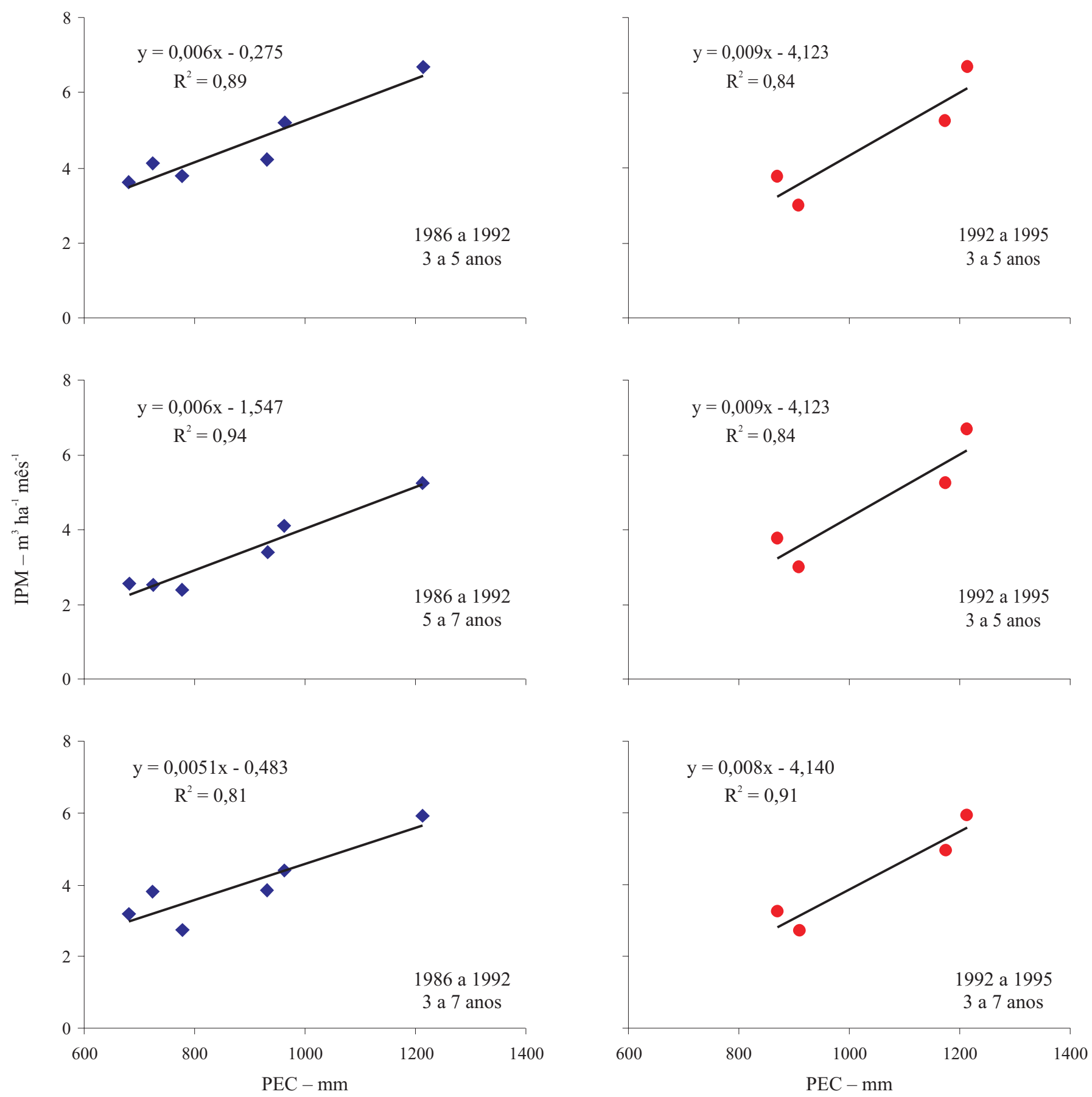

Figura 9. Correlação linear e coeficiente de determinação $\left(R^{2}\right)$ obtidos durante os períodos de aumento, 1986 a 1992 , e diminuição, de 1992 a 1995 , da precipitação total na estação chuvosa (PEC), em Guanhães, Minas Gerais, para as três faixas etárias 
de 100 mm na PEC. No período de redução anual da PEC (1992 a 1995) entretanto, obteve-se uma redução de volume de 0,80 e de $0,70 \mathrm{~m}^{3}$ ha $^{-1}$ mês $^{-1}$, para as faixas etárias de 3 a 5 e de 5 a 7 anos, respectivamente tendo, para a faixa etária de 3 a 7 anos, redução de volume de $0,80 \mathrm{~m}^{3} \mathrm{ha}^{-1} \mathrm{mês}^{-1}$, para uma diminuição de $100 \mathrm{~mm}$ na PEC. Observa-se ainda que a taxa de aumento no IPM, ocasionada pelo aumento anual na PEC, é diferente da taxa de redução no IPM, proporcionada pela diminuição anual da PEC.

Quanto ao potencial produtivo da região de Guanhães, este apresentou um índice de local, valor médio de todos os lotes envolvidos no estudo, igual 28,90 (CV de 13,4\%). Ressalta-se que o índice de local e a produtividade do local refletem as condições do meio ambiente, como um todo, e não somente os efeitos do clima, sofrendo a influência de outros fatores ambientais, isto é, dos fisiográficos, edáficos e bióticos.

\section{CONCLUSÕES}

1. O incremento periódico mensal (IPM) é maior para a faixa etária de 3 a 5 anos do que para a de 5 a 7 anos, tendo como valores médios, respectivamente, 4,46 e 3,67 m ha-1 mês ${ }^{-1}$.

2. O comportamento ao longo do período estudado é o mesmo para as duas faixas etárias, com aumento no IPM ao longo dos anos de 1986 a 1992 e redução no IPM de 1992 a 1996.

3. A produtividade de madeira é influenciada pelo total precipitado durante a estação chuvosa. Nos anos precedidos de estação chuvosa, classificada como seca (S) ou muito seca (MS), ocorrer queda na taxa de ganho de volume de madeira; por outro lado, nos anos precedidos de estações chuvosas, clasificadas como chuvosa (C) ou muito chuvosa (MC), ocore maior taxa de crescimento.

4. A resposta da taxa de crescimento depende da condição hídrica do solo no ano anterior, não havendo uma recomposição imediata do aparato fotossintético.

5. Para os diferentes anos verifica-se correlação positiva entre o total precipitado durante a estação chuvosa, finalizada em cada ano (PEC), e o ganho de volume.

6. A correlação entre o IPM com os períodos de aumento na PEC (1986 a 1992) e de diminuição na PEC (1992 a 1996), para Guanhães, apresenta um $\mathrm{R}^{2}$ acima de $80 \%$.

7. Um aumento de $100 \mathrm{~mm}$ na PEC representa um ganho de volume médio correspondente a $0,51 \mathrm{~m}^{3} \mathrm{ha}^{-1} \mathrm{mês}^{-1}$; entretanto, para o período de redução anual da PEC (1992 a 1995), a redução de volume é de $0,80 \mathrm{~m}^{3} \mathrm{ha}^{-1} \mathrm{mês}^{-1}$ para diminuição de $100 \mathrm{~mm}$ na PEC.

\section{AGRADECIMENTOS}

À Coordenação de Aperfeiçoamento de Pessoal de Nível Superior (CAPES) pelo financiamento desta pesquisa. À Empresa Florestal Celulose Nipo-Brasileira - CENIBRA, pelo fornecimento dos dados.

\section{LITERATURA CITADA}

Bergh, J.; McCmurtrie, R. E.; Linder, S. Climatic factors controlling the productivity of Norway spruce: A model-based analysis. Forest Ecology and Management, Amsterdã, v.110, n.2, p.127-139, 1998.

Billings, W. D. The environmental complex in relation to plant growth and distribution. The Quarterly Review of Biology, Chicago, v.27, n.3, p.251-264, 1952.

Campos, J. C. C. Principais fatores do meio que afetam o crescimento das árvores. Floresta, v.2, n.3, p.45-52, 1970.

Campos, J. C. C.; Leite, H. G. Mensuração florestal: perguntas e respostas. Viçosa: UFV, 2002. 407p.

Doorenbos, J.; Kassam, A. H. Yield response to water. Rome: FAO, 1979. 306p. Irrigation and drainage, 33

Maestri, R. Modelo de Crescimento e produção para povoamentos clonais de Eucalyptus grandis considerando variáveis ambientais. Curitiba: UFPR, 2003. 143p. Tese Doutorado

Neves, J. C. L. Produção e partição de biomassa, aspectos nutricionais e hídricos em plantios clonais de eucalipto na região litorânea do Espírito Santo. Campos: UENF, 2000. 191p. Tese Doutorado

O’Brien, M. J. P. Ecologia e modelamento de florestas tropicias. Belém: FCAP, 1995. 400p.

Pereira, A. R.; Angelocci, L. R.; Sentelhas, P. C. Agrometeorologia, fundamentos e aplicações práticas. Guaíba: Livraria e Editora Agropecuária Ltda. 2002. 478p.

Pinkayan, S. Conditional probabilities of occurrence of wed and dry years over a large continental area. Boulder: Colorado State University, 1966. Hidrology Papers, 12

Sacramento Neto, O. B. Balanço hídrico em plantios jovens de eucalipto na região de Belo Oriente, MG. Viçosa: UFV, 2001. 77p. Dissertação Mestrado

Sands, R.; Mulligan, D. R. Water and nutrient dynamics and tree growth. Forest Ecology and Management, Amsterdã, v.30, n.1, p.91-111, 1990.

Sellers, W. D., Fhysical climatology. Chicago \& London: Universidade de Chicago. 1965. 272p.

Soares, C. P. B. Um modelo para o gerenciamento da produção de madeira em plantios comerciais de eucalipto. Viçosa: UFV, 1999. 71p. Tese Doutorado

Stape, J. L. Production Ecology of clonal Eucalyptus Plantation in northeastern Brazil: 2002. 225p. Fort Collins:Post Doctoral Repost. Colorado University.

Stape, J. L.; Gomes, A. N. Influência dos estresses hídricos e nutricionais no crescimento de plantios de eucaliptos no nordeste do Brasil. In: Congresso Latino Americano de Ciência do Solo, 10, 1996, Águas de Lindóia. Anais... Águas de Lindóia, SBCS.1996. CD-Rom

Souza, M. J. H., Ribeiro, A., Leite, F. P. Balanço Hídrico e Caracterização Climática de Guanhães, Nova Era e Rio Doce. In: Congresso Brasileiro de Agrometeorologia, 13, 2003, Santa Maria, Anais... Santa Maria: SBA, , 2003, p.131-132.

Souza, M. J. H., Ribeiro, A., Leite, H. G., Leite, F. P., Minuzzi, R. B. Disponibilidade hídrica do solo e produtividade do eucalipto em três regiões da bacia do Rio Doce. Revista Árvore, Viçosa, v.30, n.3, p.399-410, 2006.

R. Bras. Eng. Agríc. Ambiental, v.10, n.3, p.629-638, 2006. 
Teixeira, H. C. T.; Azevedo, P. V. Potencial agroclimático do Estado do Pernambuco para o cultivo de acerola. Revista Brasileira da Agrometeorologia, Santa Maria, v.2, n.1, p.105-113, 1994.

Thornthwaite, C. W.; Mather, J. R. The water balance. Publication in climatology: Cencerton, New Jersey, v.8, n.1, 1955.

Vianello, R. L.; Alves, A. R. Meteorologia básica e aplicações. Viçosa: Imprensa Universitária. 1991. 449p.

Vose, J. M.; Swank, W. T. Effect of long-term drought on the hydrology and growth of a white pine plantation in the southern Appalachians. Forest Ecology and Management, Amsterdã, v.64, n.1, p.25-39, 1994.
Woollons, R. C.; Snowdon, P.; Mitchell, N. C. Augmenting empirical stans projections with edaphic and climatic variable. Forest Ecology and Management, Amsterdã, v.98, n.3, p.267-275, 1997.

Xavier, T. de M. B. S. Tempo de chuva: estudos climáticos e de previsão para o Ceará e nordeste setentrional. Fortaleza: ABC Editora. 2001. 476p.

Yet, H. Y.; Wensel, L. C.; Turnblom, E. C. An objective approach for classifying precipitation patterns to study climatic effects on tree growth. Forest Ecology and Management, Amsterdã, v.139, n.1, p.41-50, 2000. 